Research article

\title{
Management feasibility of established invasive plant species in Queensland, Australia: A stakeholders' perspective
}

\author{
Olusegun O. Osunkoya ${ }^{\mathrm{a}, *}$, Jens G. Froese ${ }^{\mathrm{b}}$, Sam Nicol ${ }^{\mathrm{c}}$ \\ ${ }^{a}$ Invasive Plant and Animal Science Unit, Biosecurity Sciences, Queensland Department of Agriculture and Fisheries, Eco-sciences Precinct, Brisbane, QLD 4102, Australia \\ ${ }^{\mathrm{b}}$ CSIRO Health and Biosecurity, Eco-sciences Precinct, Brisbane, QLD 4102, Australia \\ ${ }^{\mathrm{C}}$ CSIRO Land and Water, Eco-sciences Precinct, Brisbane, QLD 4102, Australia
}

\section{A R T I C L E I N F O}

\section{Keywords:}

Australia

Expert elicitation

Management feasibility

Prioritization

Stakeholders

Weed control options

Pest risk assessment

\begin{abstract}
A B S T R A C T
Managing and monitoring invasive alien species (IAS) is costly, and because resources are limited, prioritization decisions are required for planning and management. We present findings on plant pest prioritization for 63 established invader species of natural and grazing ecosystems of Queensland, Australia. We used an expert elicitation approach to assess risk (species occurrence, spread, and impact) and feasibility of control for each IAS. We elicit semi-quantitative responses from diverse expert stakeholders to score IAS on three management approaches (biocontrol, chemical and mechanical) in relation to cost, effectiveness and practicality, and incorporate uncertainty in expert inputs and model outputs. In the process, we look for promising management opportunities as well as seek general trends across species' ecological groups and management methods. Stakeholders were cautiously optimistic about the feasibility of managing IAS. Taking into consideration all factors, the overall feasibility of control was uncorrelated with the stakeholders' level of confidence. However, within individual management criterion, positive trend was observed for the same bivariate traits for chemical control, and negative trends for biocontrol and mechanical controls. Utility and confidence in IAS management options were in the order: chemical > biocontrol = mechanical, with practicality and effectiveness being the main driver components. Management feasibility differed significantly between IAS life forms but not between habitats invaded. Lastly, we combined IAS risk assessment and management feasibility scores to create a risk matrix to guide policy goals (i.e. eradication, spread containment, protection of sensitive sites, targeted control, site management, monitoring, and limited action). The matrix identifies promising species to target for each of these policy outcomes. Overall, our general approach illustrates (i) the importance of understanding the feasibility of IAS control actions and the factors that drive it, and (ii) demonstrates how quantifying management feasibility can be used to enhance traditional risk assessment rankings to improve policy outcomes.
\end{abstract}

\section{Introduction}

In any societal endeavour, as resources become more limited, prioritization becomes the norm. Where prioritization decisions are urgent and imperative, the necessary empirical data may be lacking and the use of objective facts and stakeholders' inputs are often called upon (Downey et al., 2010; Booy et al., 2017; Hemming et al., 2018). Prioritization, especially in a biosecurity setting (here, we use the word 'biosecurity' in the context of management of invasive alien species), allocates resources so that investment produces maximum net benefit and allows (i) a more efficient resource allocation, (ii) a transparent basis for decision making, (iii) conceptualization of the problem, and (iv) a quantitative aid to decision making where there are conflicting objectives that are measured in different units (e.g. consider control of a biological invasion under conflicting/differing needs such as maximal ecological integrity and human health with that relating to minimal agricultural economic loss). In many cases, prioritization using a participatory approach by an assessment committee differs from ongoing resource allocation based on ad-hoc narrative-based assessment (Cook and Proctor, 2007; Kumschick et al.,2012; Lodge et al., 2016).

Prioritization of invasive alien species (IAS) considers many species simultaneously, each of which is likely to be widely distributed across large spatial domains. Although some IAS are likely to be well-studied, for many species formal quantitative data are unlikely to be available (Barney et al., 2013; Pearson et al., 2016). However, IAS managers and researchers hold a wealth of tacit knowledge about IAS that is used to manage these species in practice. Formal expert elicitation techniques provide a means to extract this information from experts and use it in a

\footnotetext{
* Corresponding author.

E-mail address: olusegun.osunkoya@daf.qld.gov.au (O.O. Osunkoya).
} 
collaborative setting to evaluate relative risks of IAS (Hemming et al., 2018). Although expert elicitation is subject to some limitations, such as judgement biases (Martin et al., 2012), it has at least three clear advantages for IAS prioritization. Firstly, it provides a formal, justifiable and accountable approach to decision-making despite the absence of data. Secondly, it provides a forum for experts to collaborate, examine their assumptions with peers and reach consensus decisions. Finally, expert elicitation is a general approach that can be applied in many different application domains and jurisdictions-for example, the method that we describe in this study (see the Methods section) can be applied to prioritize IAS control in other jurisdictions where expertise is available but formal data are lacking.

Most prioritization on IAS are based on the concept of risk rating - a product of probability of exposure and severity of the impact of that exposure (Leung et al., 2012; Osunkoya et al., 2018). However, many prioritizations of pests, including post-border weed risk systems, rarely assess the feasibility of managing those risks (Randall et al., 2008; Kumschick et al.,2012; Auld and Johnson, 2014; Booy et al., 2017). Both risk assessment and management feasibility are essential for effective prioritization: the risk assessment examines the threat or hazard, while the risk management evaluates and informs cost-effective management options. It has been argued that not including feasibility of management in pest risk decision is likely to produce a sub-optimal outcome (Heikkilä, 2011; Auld and Johnson, 2014) (see also https:// ipmdat.org/index.html- accessed Feb 15, 2019).

Along with the rating scheme, uncertainty in data inputs (e.g., where there is a low confidence attached to a rating score) may impact on the model outputs (e.g., the ranking produced of risk-assessed species) following the prioritization for management. Hence uncertainty in data inputs is intrinsically associated with assigned risk, and consideration of uncertainty is an important requirement to ensure that priorities are consistent and robust to variations in input information. Uncertainty in IAS listing processes can be associated with lack of information, conflicting evidence, context dependence or unclear formulations (Liu et al., 2011; Leung et al., 2012; McGeoch et al., 2012; Caton et al., 2018). Uncertainty complicates decisions (Caton et al., 2018) but it needs to be explicitly integrated in pest risk prioritization.

In an earlier work (Osunkoya et al., 2018; 2019), weed risk assessment and prioritization of 103 established IAS of the State of Queensland (QLD), Australia, was undertaken based on their distribution and range (invasiveness), threat level and impact. In that exercise, we scoped local government pest management plans, herbarium records, and the published literature, then carried out a structured elicitation of expert knowledge during a series of regional stakeholder workshops across QLD. In Osunkoya et al. (2018, 2019) we hypothesised that to increase the utility of such a prioritised list for biosecurity research, management and policy, there was a need to refine the list based on feasibility of management. Booy et al. (2017) postulated that a practical risk management (feasibility estimation) scheme should be compatible with existing risk assessment schemes, benefits from use of expert judgements, be broadly applicable to any taxa, and be possible and efficient to apply even when/where empirical data are lacking as long as uncertainty in the data set are taken into account, documented and justified. To this end, in this paper we collated and used expert judgement values, including uncertainty estimation, to provide semiquantitative management scores relating to practicality, cost and efficiency for 63 of the 103 species that were risk-assessed in Osunkoya et al. (2018, 2019). These 63 species are listed as restricted or prohibited in the Queensland Biosecurity Act 2014, and hence the results of the prioritization exercise will offer opportunities for contingency planning at the State level. Our pest risk management expert elicitation workshop was backed by written comments and supported by evidence where possible (see also Leung et al., 2012; Booy et al., 2017; Hemming et al., 2018 for similar approaches).

In the course of assessing the feasibility of management for our focal IAS, we expected species-specific traits such as life form and nature of habitat invaded, as well as control history (success or otherwise elsewhere) and uncertainty in data to influence experts' opinions about the feasibility of a particular management option. We hypothesised the following:

(I) Terrestrial invasive plants, relative to aquatics, are predicted to have a higher probability of successful management. Aquatic IAS are more difficult to manage because, unlike terrestrial plants, they frequently use both sexual and asexual reproductive strategies (i.e., vegetative propagation including fragmentation of body parts, e.g., Cabomba Carolinian (Cabomba)). Aquatic IAS are also easily dispersed through lotic (flowing) water bodies and catchment areas (Bickel, 2017; Hussner et al., 2017);

(II) Managing invasive grasses relative to other plant life forms would be perceived more difficult by stakeholders due to grass species' dual capability to propagate sexually and vegetatively, and their structural simplicity and hence similarity to many co-occurring native monocot species (Pemberton, 1996; Casagrande et al., 2018). The latter factor makes many biocontrol practitioners and IAS managers to believe that natural enemies of grasses lack host specificity compared to those that feed on other plant life forms (Pemberton, 2000), and hence many practitioners and the scientific community tend to shy away from advocating the use of biological agents for invasive grass management.

(III) Control history and/or life form of an IAS would influence stakeholder's management perception, to the extent that a focal species with a congener (e.g. the Cactaceae [succulents] or Chromolaena odorata (Siam weed) that have been successfully controlled in the past, either in QLD or elsewhere (Julien et al., 2012), would be deemed to have a higher likelihood of feasibility of management into the future.

(IV) Despite societal concern about the use of chemicals in ecological systems (Osunkoya and Perrett, 2014; Davis and Frisvold, 2017), previous studies have shown that practitioner belief in the efficacy of chemicals for control of established invader plant species is very high (Wagner et al., 2017; Davis and Frisvold, 2017). Consequently, we predicted that the effectiveness of herbicide usage and confidence in its utility would be greater (i.e. of lower uncertainty) than biological or mechanical control methods. In a similar vein, we predicted that changes in the feasibility of management would match changes in the level of confidence as stakeholders develop greater awareness and expectation of a given management tool (especially chemical usage) based on proven past history and experience.

In this paper, we built on our previous work by conducting a second round of expert elicitation to compile information on the feasibility of plant pest (weed) control of existing risk-assessed IAS of QLD (Osunkoya et al., 2018; 2019). Stakeholders provided semi-quantitative scores to three traditional management methods- biocontrol, chemical and mechanical-in relation to cost, effectiveness and practicality. We also collected expert confidence in data inputs and analysed uncertainty in the aggregated final scores.

\section{Materials and methods}

\subsection{Risk assessment protocol}

Through an initial scoping work on local government pest management plans and a first round of stakeholder elicitation workshops (yr. 2016/2017) across the State, a list of 103 IAS that have established and are of significant management concern to QLD were identified, risk assessed and prioritised (Osunkoya et al., 2018; 2019). However this previous study did not quantify the feasibility of management, which is the focus of this work. Sixty three of these risk-assessed IAS are listed in the QLD Biosecurity Act 2014 as restricted/prohibited, and hence were 
selected for this work.

\subsection{Risk management protocol}

From early December 2017-late January 2018, we reviewed and trialled various pest risk management protocols (Nel et al., 2004; Heikkilä, 2011; Kumschick et al.,2012; McGeoch et al., 2016; Booy et al., 2017), and subsequently refined their published scheme, steps and scoring procedures to suit our needs. Over this eight week period, the authors and a paid facilitator developed materials for an expert elicitation workshop. During the process, we provided project description, background information, practice and elicitation questions and survey materials-all of which passed through a series of in-house reviews and refinement. We then sent personalised introductory email to potential participants of diverse scientific and weed management background, most of whom responded positively to our invitation; in rare cases we followed with phone calls.

In February 2018, we convened a second stakeholder elicitation workshop following the methodology suggested by Heikkilä (2011) and Booy et al. (2017). Twenty five stakeholders who are experts on IAS ecology and management in QLD attended the workshop. They consisted of principal biosecurity officers, agriculture/extension officers dealing with herbicide use, government scientists, and academic researchers. At the elicitation workshop, stakeholders scored candidate IAS on four key criteria (effectiveness, practicality, cost, and overall feasibility of management) relating to biological, chemical or mechanical management (Table 1; and Supplementary material S1 of Booy et al., 2017 for in-depth details of the scoring procedures). We focussed on these three main management options to allow for comparison between different traditional approaches. While the first two control options (i.e. biocontrol and chemical usage) are clear as per methodology, the last strategy (i.e., mechanical) is often diffuse and hence imprecise, ranging from short-term tactics like use of fire, to raking/bulldozing/ cutting, soil tilling and pasture management. Booy et al. (2017) suggested eight rather than the four criteria included in this work, but the excluded management criteria (action impact, acceptability, the likelihood of re-invasion, and window of opportunity of a particular management action) were not included as they have been shown by the same authors to be poor predictors of management feasibility and are, in any case, significantly correlated $(\mathrm{P}<0.05)$ to one another (e.g. management in relation to off-target impact vs. acceptability; window of opportunity vs. the likelihood of re-invasion). The large number of candidate species (63 species), and array of management options and their components (10) to consider were also determining factors of the reduced criteria assessed.

The IAS management scheme involves a series of questions supported by guidance (see Box 1 in Booy et al., 2017). The key steps in the procedure are summarised below:

(i) Providing workshop participants with the invasion scenario of each candidate species. Invasion scenarios were based on QLD pest fact sheets (https://www.business.qld.gov.au/industries/farms-fishingforestry/agriculture/land-management/health-pests-weeds-

diseases/weeds-diseases/invasive-plants- accessed Feb 18, 2019),
QLD annual pest distribution survey (APDS) databases, and the invasiveness/impact index of Osunkoya et al. (2018, 2019). These databases provided information on the current distribution extent of the IAS in the management area (note that due to their job description and experience, most participants were well aware of this information).

(ii) Defining the management strategy (step 2 in Booy et al., 2017). Because complete eradication is not practically achievable for many IAS (Panetta and Gooden, 2017; Jardine and Sanchirico, 2018), we assumed that the management aim is not the complete eradication of IAS from a given area, but suppression of the weed population below a given threshold ( $\leq 10 \%$ of initial population size within a management area) where damage/impact on native ecosystem, services or goods are minimised (see Osunkoya et al., 2013; Panetta and Gooden, 2017). Defining the management strategy (i.e. at/ below a given threshold) at this point allows for assumptions to be highlighted and documented upfront, clarifying the decision context for the rest of the assessment.

At the one-day workshop, with a paid facilitator (to guide but not to dominate the discussion), the context of the elicitation and the IAS risk assessment rankings (a product of invasiveness and impact) from the previous workshop (see Osunkoya et al., 2018; 2019) were introduced to participants. This served to clarify the method and enable experts to ask questions. Practice questions were also presented and undertaken for clarity and to reduce ambiguity in response score. Prior to the workshop, we divided the participants into three groups $(\mathrm{N}=6-8$ per group) ensuring that each group had an appropriate diversity of expertise/knowledge in species distribution (i.e. ecology), biocontrol, mechanical and chemical control of weeds. The subgroups of 6-8 participants were then presented with 20-22 species to score (see below) using a consensus approach. The structured use of group rather than individuals to produce consensus scores allowed us to (i) combine expert elicitation with review and consensus building to minimise the impact of "expert anchoring" "groupthink syndrome", lack of representativeness, over confidence, communication difficulty, and poorly worded/ambiguous questions (Martin et al., 2012; Burgman, 2015; Hemming et al., 2018), and (ii) have a transparent, documented justification of all scores.

For each assigned IAS, a consensus response was provided by each subgroup for each of the three management options and their components. Consensus responses were also provided for the overall feasibility of control, taking into account all management factors. Written justifications for responses were recorded where required. Response scores were ordinal on a five point scale (Table 1 ). The ordinal scale was predefined using descriptive terms (Baker et al., 2012; Booy et al., 2017) except for cost, which was based on quantified/calibrated bands derived from consultations with decision makers on the QLD State budget for IAS control (Steve Cshurhes and Joe Vitelli, per. communication). Confidence scores were also explicitly recorded for every response using a three point scale (Low-Medium-High) based on guidance provided by the Intergovernmental Panel on Climate Change (Mastradrea et al., 2011; Caton et al., 2018).

After completing the scoring, the subgroups reconvened as a single

Table 1

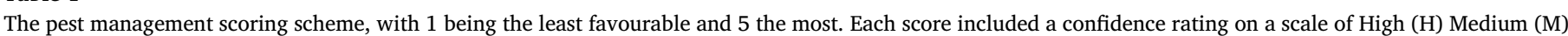
and Low (L).

\begin{tabular}{|c|c|c|c|c|c|}
\hline \multirow[t]{2}{*}{ Criterion } & \multicolumn{5}{|l|}{ Response score } \\
\hline & 1 & 2 & 3 & 4 & 5 \\
\hline Effectiveness & Very ineffective & Ineffective & Moderate effectiveness & Effective & Very effective \\
\hline Practicality & Very impractical & Impractical & Moderate Practical & Practical & Very practical \\
\hline Cost (per ha.) (Australian \$) & Massive $(>\$ 10,000)$ & Major $(\$ 5,000-10,000)$ & Moderate $(\$ 1,000-5,000)$ & Minor $(\$ 250-1,000)$ & Minimal $(<\$ 250.00)$ \\
\hline Conclusion (Overall feasibility of control) & Very low & Low & Medium & High & Very high \\
\hline
\end{tabular}



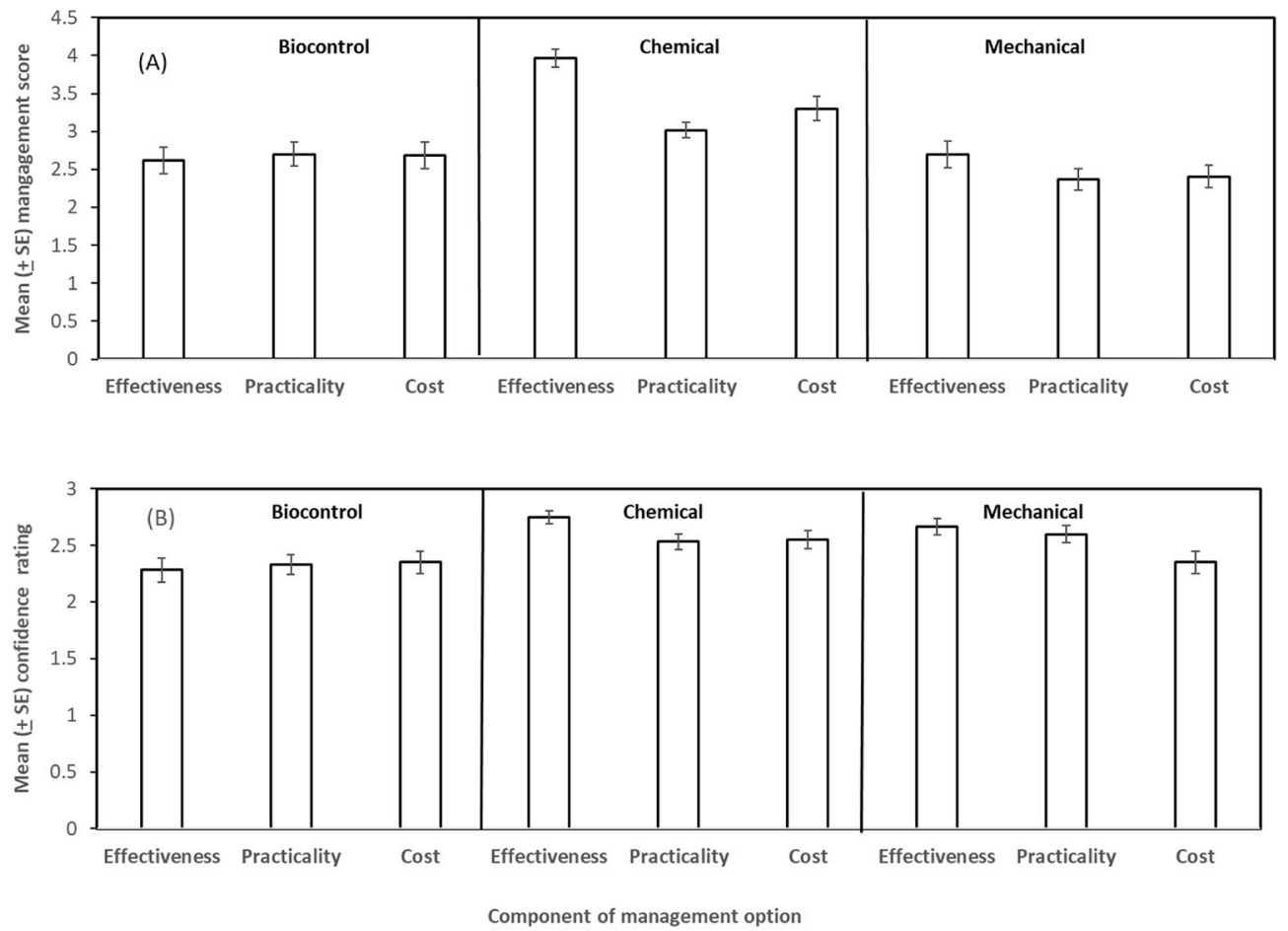

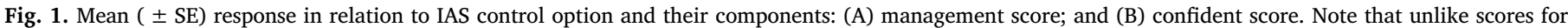
management components of practicality and effectiveness, higher score for cost is the desirable option as it implies decreasing spending.

group, and each subgroup (through a leader) presented and justified their scores to all participants. During this stage every participant was directly invited to comment on or challenge each score, thus encouraging consistency in scoring between subgroups. Thereafter, the subgroups were reformed for a second break-out session to discuss and alter scores if necessary. In the last phase of the workshop, the facilitator presented the refined (consensus) scores of all species to all participants.

\subsection{Data analysis}

We used a Bayesian one-way ANOVA approach to test for differences in the ordinal scores and confidence ratings between management options/components, between life forms and between habitats invaded. Polychoric correlation was used to examine the relationships amongst the ordinal management criteria/components (Baglin, 2014). To summarize and explore trends in the dataset, the management scores, except for overall feasibility of control, were subjected to exploratory factor analysis (EFA) (Lorenzo-Seva and Ferrando 2006)- a multivariate technique that is used extensively in the field of assessment and evaluation (Baglin, 2014). Thereafter, the relationship between the major axes produced (denoted as I, II, and III) and overall feasibility of control were tested via correlation analyses. We avoided weighting management criteria because the utility of such a methodology in risk ranking is debateable (see Heikkilä, 2011; Kumschick et al.,2012; Vanderhoeven et al., 2017; Caton et al., 2018); rather we integrated the management components and estimated the return on investment (ROI) for each management option as a product of effectiveness and practicality standardized by cost (i.e.: $\mathrm{ROI}=$ (effectiveness*practicality)/cost) (Firn et al., 2015). To indicate priorities for management, a matrix was created to compare overall feasibility of control (or ROI) with existing risk assessment scores detailed in Osunkoya et al. (2018, 2019). As in the national post-border weed risk management protocol standards of Australia (Anonymous, 2006) and Booy et al. (2017), species that simultaneously scored highest in terms of risk assessment and feasibility of control (or ROI) will be recommended for the greatest priority, while those that scored less were assigned lower priority (see also https://ipmdat.org/index.htmlaccessed February 10, 2019).

We used the simulation method described in Caton et al. (2018) to analyse expert uncertainty about the management options, their components, and overall feasibility of control for each species. Each simulation consisted of four steps. Firstly, we used the expert uncertainty scores ( $\mathrm{L}, \mathrm{M}$ or $\mathrm{H}$ ) to determine the probability that the expert score (1-5) would change from the specified value. Each uncertainty score corresponded to a triangular distribution with parameters specified by Caton et al. (2018); these represent the probability that the overall ranking would change and are included in Appendix S1 of the supporting information. Secondly, we randomly drew a value from the appropriate triangular distribution and used this value as the probability of success in a Bernoulli trial to determine whether or not the ranking would change. Thirdly, we determined the simulated score using the outcome of the Bernoulli trial. If the Bernoulli outcome was 0 (failure), then the simulated ranking was equivalent to the expert-specified ranking. If the outcome was 1 (success), then a new simulated ranking was selected according to a transition matrix based on the probabilities specified in Caton et al. (2018) (Appendix S1). Unlike Caton et al. (2018), experts did not specify the second- and third-most likely outcomes explicitly, but we assumed that if expert estimates were wrong, the next most likely outcome was the outcome adjacent to the estimate (e.g. if the estimated score was 5 and was changed in the simulation, then the next most likely score was 4 , followed by 3 ). Where there were two adjacent outcomes (e.g. if the estimated score was 3, the two adjacent outcomes are 2 and 4), we assumed that each was equally likely. We further assumed that all outcomes were reachable, assigning all states with a minimum probability of 0.01 and adjusting the other probabilities accordingly to ensure that the probabilities of transition summed to 1 . The complete transition matrix is included in Appendix S1 of the supporting information. Finally, we repeated the first three steps 100 times to generate a simulated dataset of 100 overall ranking outcomes. We used this simulated dataset to generate an estimate of how expert-stated uncertainty might affect the distribution of 

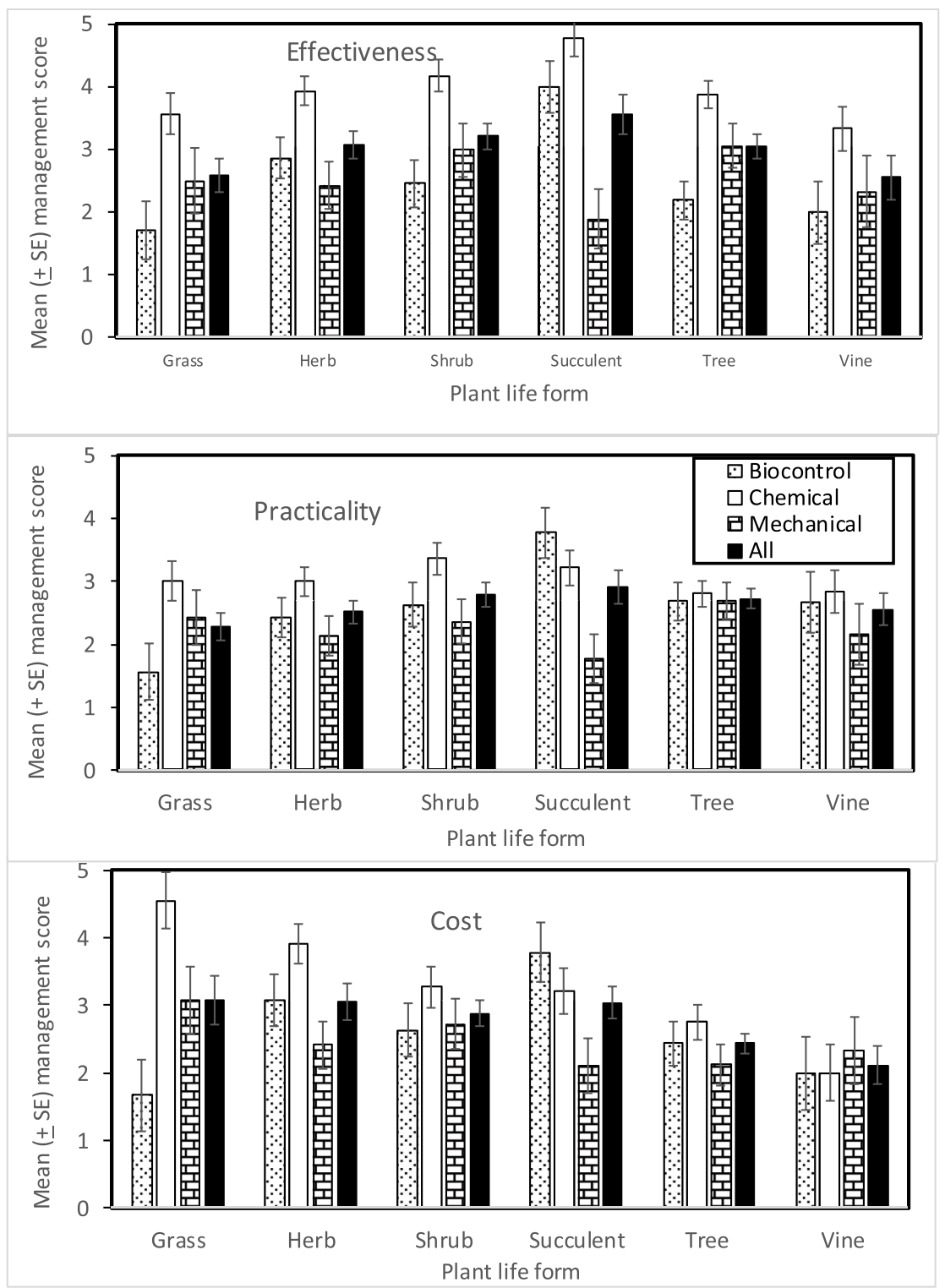

Fig. 2. Mean ( \pm SE) of components of IAS management scores in relation to plant life forms. Note that unlike scores for management components of practicality and effectiveness, higher score for cost is the desirable option as it implies decreasing spending.

management actions and the overall feasibility of control, and measured this variability using the standard deviation of the outcomes in the simulated dataset.

\section{Results}

\subsection{Weed risk management scores}

Mean management score (on a scale of $1-5, \pm 95 \%$ Confidence Interval $[\mathrm{CI}])$ ) was consistently highest for the chemical control option (3.43, $\mathrm{CI}=3.26-3.61) \quad$ in comparison to biocontrol (2.61, $\mathrm{CI}=2.43-2.78)$ and mechanical $(2.44, \mathrm{CI}=2.26-2.61)$ (Bayesian ANOVA: $\left.\mathrm{F}_{2,555}=35.82, \mathrm{P}=0.0001\right)$. Chemical control scored highest on all three management components: it was the cheapest, most effective and most practical option (Fig. 1a).

The mean management score distribution differed amongst life forms $\left(F_{5}, 555=2.89 ; \mathrm{P}=0.014\right)$, with a tendency for higher (more effective management) mean scores for succulents and shrubs and lowest (least effective management) values for trees, vines and grasses (Fig. 2). However, this general trend is dependent on the management criterion; it was most consistent for biocontrol. The mean ( $\pm \mathrm{SE}$ ) management scores, irrespective of control option, did not differ significantly between main form of habitat invaded (terrestrial vs aquatic: $2.87 \pm 0.61$ vs $2.63 \pm 0.13 ; \mathrm{F}_{1,562}=2.70 ; \mathrm{P}=0.10$ ).

The score for overall feasibility of control was most strongly correlated with the risk management components of chemical control (especially effectiveness $[r=0.67]$ and practicality $[r=0.63]$ ) (Table 2). We detected no significant correlation between overall feasibility of control and perceived threat $(r=-0.192)$, invasiveness $(\mathrm{r}=-0.61)$ or impact $(\mathrm{r}=-0.168 ; \mathrm{P}>0.05$ in all cases). When scores were summed across management options and overall feasibility of control, the grand score for the 63 risk-assessed species was of the order: very high: ( 2 species), high ( 5 species), medium (44 species), low (12 species) and negligible (2 species) (Table 3 ).

Species ordination based on the components of the management scores and using Exploratory Factor Analyses (EFA) indicated that three axes (with a total variance of $80.81 \%$ ) are required to adequately explain the variation the date set (Fig. 3). Axis I captured the largest variation in the data set $(37.7 \%)$. The driver management variables for Axis I are the three components of mechanical option. However, species 
Table 2

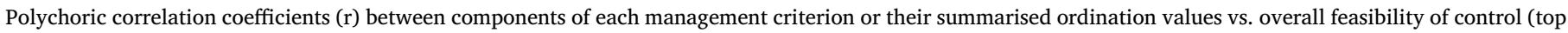

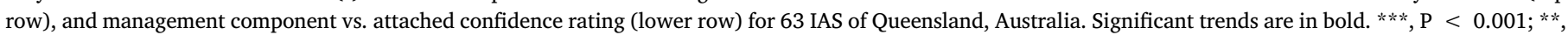
$\mathrm{P}<0.01,{ }^{*}, \mathrm{P}<0.05, \mathrm{~T}, 0.10<\mathrm{P}>0.05$

\begin{tabular}{|c|c|c|c|c|c|c|c|c|c|c|c|c|}
\hline \multirow[t]{3}{*}{ Trait } & \multicolumn{9}{|c|}{ Management assessment score } & \multicolumn{3}{|c|}{$\begin{array}{l}\text { Ordination of management } \\
\text {-assessment scores }\end{array}$} \\
\hline & \multicolumn{3}{|l|}{ Biocontrol } & \multicolumn{3}{|l|}{ Chemical } & \multicolumn{3}{|l|}{ Mechanical } & \multirow[b]{2}{*}{ Axis I } & \multirow[b]{2}{*}{ Axis II } & \multirow[b]{2}{*}{ Axis III } \\
\hline & Effectiveness & Practicality & Cost & Effectiveness & Practicality & Cost & Effectiveness & Practicality & Cost & & & \\
\hline $\begin{array}{l}\text { Overall feasibility of } \\
\text { control }\end{array}$ & $0.415^{* *}$ & 0.164 & $0.306^{*}$ & $0.674 * * *$ & $0.634 * * *$ & $0.397 * *$ & 0.151 & 0.171 & 0.137 & 0.11 & $0.310 *$ & $0.561 * * *$ \\
\hline $\begin{array}{l}\text { Confidence in } \\
\text { management } \\
\text { assessment score }\end{array}$ & -0.004 & $-0.368^{* *}$ & $-0.221 \uparrow$ & $0.209 \uparrow$ & 0.151 & $0.22 \uparrow$ & -0.069 & $-0.34^{*}$ & $-0.333^{*}$ & - & - & - \\
\hline
\end{tabular}

scores on Axis I were not significantly correlated with the overall feasibility of control score $(r=0.11, \mathrm{~N}=63, \mathrm{P}=0.29$; Table 2$)$, so Axis I was discarded (i.e., species ordination on this axis is not presented). Axis II captured a lesser proportion (27.6\%) of the data variation but was significantly correlated with the overall feasibility of control score (Fig. 3 and Table 2). The three components of the biocontrol option were the major drivers of Axis II. Axis III captured an even lesser proportion of the data variation (15.52\%), but like Axis II was significantly correlated with the overall feasibility of control scores (Fig. 3 and Table 2). The components of the chemical control were the dominant driver variables of Axis III (Fig. 3). In summary, of the three main/ explanatory axes, Axis III (the chemical axis) had the greatest correlation with the overall feasibility of control $(\mathrm{r}=0.56$; $\mathrm{P}=0.0001)$, followed by axis II (the biocontrol axis: $\mathrm{r}=0.31$; $\mathrm{P}=0.01$ ), while axis I (the mechanical axis) showed no significant relationship ( $\mathrm{r}=0.11$; $\mathrm{P}=0.29$ ) (Table 2; Fig. 3). This may reflect the stakeholders' perception that chemical (i.e., herbicide) use offered the best management panacea to control established plant pests, just as detected in the univariate analysis presented in the preceding paragraph (Fig. 1). Thus the EFA ordination showed that the overall assessment of feasibility of control broadly relates most to the underlying components scores along Axis III (chemical) and to a limited extent Axis II (biocontrol).

In terms of life forms, only the ordination scores of IAS on Axis II (the biocontrol axis) indicated significant difference $(P=0.004)$, with success for use of biocontrol option being perceived more for succulents and least for grasses (Appendix S2). Axis III (the chemical control axis) also showed a marginal effect $(\mathrm{P}=0.09)$ of life form with vines and trees loading negatively (less control using chemical), while the remaining life forms loaded positively (greater control) on this chemical control axis (Appendix S2).

\subsection{Uncertainty in weed risk management scores}

Confidence scores (on a scale of 1-3) followed a similar trend as that of the management scores: ratings differed between management options (1-way ANOVA: $\mathrm{F}_{2,564}=9.52, \mathrm{P}=0.001$ ), and experts were most confident about chemical and mechanical management (mean ratingchemical: 2.62, $\mathrm{CI}=2.52-2.72 ; \quad$ and mechanical: 2.56, $\mathrm{CI}=2.47-2.66$ ), but were significantly less confident about biocontrol (mean 2.30, CI $=2.23-2.42$ ) (Fig. 1b). At the individual species level, increased overall feasibility of control did not translate to increased overall confidence score $(\mathrm{r}=0.018 ; \mathrm{n}=63 ; \mathrm{P}=0.89)$. However, within individual management criteria, significant positive associations (albeit marginally) exist between management component score and their confidence rating for chemical control (range, $r$ : $0.15-0.22 ; \mathrm{P} \leq 0$ 0.10 ), while those of biocontrol and mechanical control indicated significant negative trends (range, $\mathrm{r}:-0.37$ to $-0.2 ; \mathrm{P}<0.10$ ) (Table 2 ).

\subsection{Return on investment (ROI)}

As expected, ROI (a product of management effectiveness and practicality standardized by cost and adjusted for expert uncertainty; see Firn et al., 2015 and Caton et al., 2018) varied significantly between species, between life forms and management options (Appendix S3). Static ROI (Benefit $\$$ ) was greatest for chemical control (41.81 \pm 3.17), intermediate for biocontrol $(27.64 \pm 4.00)$ and least for mechanical control $(21.89 \pm 2.91)$. The top ten IAS in terms of ROI in control options are listed in Table 4. In the following text, the number in square bracket indicates species number in Table 3. The listed species varied across the three management options, except for (i) Parthenium hysterophorus (Parthenium) [1] which expert stakeholders believed can be equally managed using the three options, (ii) Mimosa invisa (giant sensitive plant) [54], Salvinia molesta (salvinia) [13] and Eichhornia crassipes (water hyacinth [16] which are better managed by both biological and chemical control options, and (iii) Parkinsonia aculeata (Parkinsonia) [4] and Ambrosia artemisiifolia (annual ragweed) [39] that are better managed by both chemical and mechanical options.

\subsection{The weed risk prioritization matrix}

Following adjustment for expert uncertainty, the mean score for overall feasibility of management (i.e. risk management scores) were plotted against the overall risk assessment (i.e. invasiveness or impact) scores of Osunkoya et al. $(2018,2019)$ to produce a prioritization matrix (Fig. 4). There was no demonstrated correlation between the two forms of risk analyses $(\mathrm{r}=0.06, \mathrm{~N}=63$; $\mathrm{P}>0.05)$, but the combination of the two provided information not apparent when considering either in isolation. Overall, 19 of the 63 species, irrespective of control method, scored high or very high for feasibility of control (Fig. 4). A total of 22 species had negligible (3 species) and low management (19 species) feasibility scores, respectively. The remaining 22 IAS were in between the two management feasibility extremes (Fig. 4). In the following text, the numbers in square brackets indicate the labelled species number on Fig. 4 and in Table 3. Thus using this matrix table, and based on Australia and New Zealand generic risk management standard (Anonymous, 2006; Downey et al., 2010), managing high impact and/or high invasiveness species like Parthenium hysterophorus (Parthenium) [1], Parkinsonia aculeata (Parkinsonia) [4], Sporobolus pyramidalis and $S$. natalensis (giant rat's tail grasses) [6] and Cryptostegia grandiflora (rubber vine)[3] will require site/regional-specific eradication, spread containment measure and/or protection of sensitive sites; Species like Mimosa invisa (giant sensitive plant) [54], Opuntia microdasys (bunny ears) [50] and Opuntia aurantiaca (Tiger pear) [60] despite their high feasibility of management may only require being kept under a watchful eye due to their low invasiveness and/or impact. In contrast, Gymnocoronis spilanthoides (Senegal tea) [34], Cabomba caroliniana (Cabomba) [21], Hygrophila costata (Hygrophila) [41], Anredera cordifolia (Madeira vine) [23], and Thunbergia 
Table 3

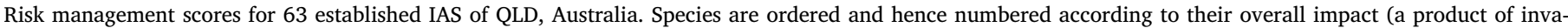

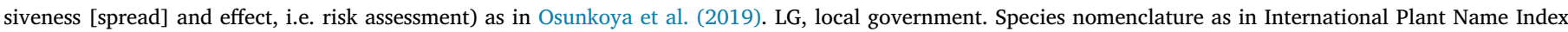

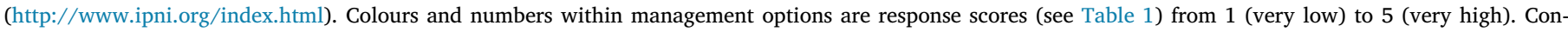

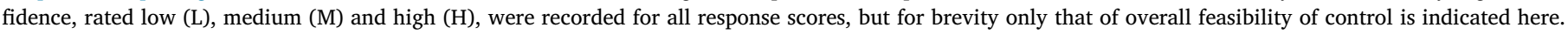

\begin{tabular}{|c|c|c|c|c|c|c|c|c|c|c|c|c|c|c|c|c|c|}
\hline \multirow[b]{3}{*}{ No Species Scientific Name } & \multirow[b]{3}{*}{$\begin{array}{l}\text { Species common } \\
\text { name }\end{array}$} & \multirow[b]{3}{*}{$\begin{array}{l}\text { Species } \\
\text { Life form }\end{array}$} & & & & & \multicolumn{9}{|c|}{ Management option } & \multirow{2}{*}{\multicolumn{2}{|c|}{$\frac{\text { Overall }}{\text { Feasib-Confid- }}$}} \\
\hline & & & \multicolumn{4}{|c|}{ Invasion scenario } & \multicolumn{3}{|c|}{ Biocontrol } & \multicolumn{3}{|c|}{ Chemical } & \multicolumn{3}{|c|}{ Mechanical } & & \\
\hline & & & $\begin{array}{c}\text { No of } \\
\text { LG } \\
\text { with } \\
\text { IAS }\end{array}$ & $\begin{array}{l}\text { No of } \\
\text { region } \\
\text { with } \\
\text { IAS }\end{array}$ & $\begin{array}{c}\text { Invasive- } \\
\text { ness } \\
\text { score }\end{array}$ & $\begin{array}{c}\text { Overall } \\
\text { impact } \\
\text { score }\end{array}$ & $\begin{array}{l}\text { Effect- } \\
\text { iveness }\end{array}$ & $\begin{array}{l}\text { Pract- } \\
\text { icality }\end{array}$ & Cost & $\begin{array}{l}\text { Effect- } \\
\text { iveness }\end{array}$ & $\begin{array}{l}\text { Pract- } \\
\text { icality }\end{array}$ & Cost & $\begin{array}{l}\text { Effect- } \\
\text { iveness }\end{array}$ & $\begin{array}{l}\text { Pract- } \\
\text { icality }\end{array}$ & $\operatorname{Cos} t$ & control & \\
\hline $\begin{array}{l}1 \text { Parthenium } \\
\text { hysterophorus }\end{array}$ & Parthenium & Herb & 41 & 7 & 4.079 & 0.419 & 4 & 3 & 5 & 5 & 3 & 5 & 5 & 5 & 5 & 5 & $\mathrm{H}$ \\
\hline 2 Vachellia nilotica & Prickly acacia & Tree & 25 & 6 & 2.494 & 0.333 & 3 & 4 & 3 & 4 & 3 & 2 & 3 & 3 & 2 & 2 & $M$ \\
\hline $\begin{array}{l}3 \text { Cryptostegia } \\
\text { grandiflora }\end{array}$ & Rubber vine & Vine & 34 & 7 & 3.508 & 0.313 & 3 & 3 & 1 & 5 & 4 & 3 & 5 & 4 & 3 & 4 & $\mathrm{H}$ \\
\hline 4 Parkinsonia aculeata & Parkinsonia & Tree & 29 & 6 & 2.64 & 0.300 & 2 & 2 & 5 & 5 & 4 & 4 & 5 & 3 & 4 & 4 & $\mathrm{H}$ \\
\hline 5 Jatropha gossypifolia & Bellyache bush & Tree & 23 & 5 & 1.962 & 0.274 & 4 & 4 & 3 & 3 & 2 & 2 & 2 & 2 & 2 & 2 & $\mathrm{H}$ \\
\hline $\begin{array}{l}6 \text { Sporobolus pyramidalis } \\
\text { \& S. natalensis }\end{array}$ & $\begin{array}{l}\text { Giant rat's tail } \\
\text { grass }\end{array}$ & Grass & 25 & 6 & 2.376 & 0.268 & 4 & 3 & 2 & 3 & 3 & 5 & 3 & 3 & 3 & 2 & $\mathrm{H}$ \\
\hline 7 Bryophyllum spp. & Mother of millions & Succulent & 37 & 7 & 3.671 & 0.212 & 1 & 1 & 1 & 5 & 2 & 5 & 1 & 1 & 3 & 2 & $\mathrm{H}$ \\
\hline $\begin{array}{l}8 \text { Prosopis glandulosa, } P \text {. } \\
\text { pallida \& } P \text {. velutina }\end{array}$ & Mesquite & Tree & 23 & 4 & 1.238 & 0.195 & 3 & 3 & 3 & 4 & 2 & 2 & 3 & 3 & 2 & 2 & M \\
\hline 9 Ziziphus mauritiana & Chinee apple & Tree & 17 & 4 & 1.227 & 0.180 & 3 & 3 & 2 & 3 & 3 & 3 & 5 & 4 & 4 & 3 & $\mathrm{H}$ \\
\hline 10 Tecoma stans & $\begin{array}{l}\text { Yellow } \\
\text { bells/Tecoma }\end{array}$ & Tree & 17 & 4 & 0.3 & 0.165 & 3 & 3 & 3 & 4 & 4 & 4 & 1 & 1 & 1 & 3 & $\mathrm{H}$ \\
\hline 11 Eriocereus spp. & Harrisia cactus & Succulent & 19 & 5 & 1.486 & 0.160 & 4 & 3 & 4 & 4 & 3 & 3 & 2 & 2 & 3 & 3 & $\mathrm{H}$ \\
\hline $\begin{array}{l}12 \text { Hymenachne } \\
\text { amplexicaulis }\end{array}$ & Hymenachne & Grass & 15 & 4 & 1.167 & 0.153 & 1 & 1 & 1 & 5 & 3 & 2 & 1 & 1 & 1 & 2 & $\mathrm{H}$ \\
\hline 13 Salvinia molesta & Salvinia & Herb & 24 & 6 & 2.177 & 0.145 & 5 & 3 & 5 & 5 & 4 & 5 & 4 & 3 & 2 & 4 & $\mathrm{H}$ \\
\hline 14 Pistia stratiotes & Water lettuce & Herb & 22 & 4 & 1.144 & 0.141 & 4 & 3 & 4 & 4 & 2 & 3 & 2 & 3 & 2 & 3 & $\mathrm{H}$ \\
\hline 15 Sporobolus fertilis & $\begin{array}{l}\text { Giant paramatta } \\
\text { grass }\end{array}$ & Grass & 1 & 1 & 0.175 & 0.140 & 3 & 3 & 2 & 3 & 3 & 5 & 3 & 3 & 3 & 2 & $\mathrm{H}$ \\
\hline 16 Eichhornia crassipes & Water hyacinth & Herb & 23 & 6 & 1.887 & 0.127 & 4 & 3 & 5 & 5 & 4 & 5 & 4 & 3 & 2 & 4 & $\mathrm{H}$ \\
\hline $\begin{array}{l}17 \text { Dolichandra unguis- } \\
\text { cati }\end{array}$ & $\begin{array}{l}\text { Cats claw creeper } \\
\text { vine }\end{array}$ & Vine & 16 & 4 & 0.8 & 0.125 & 2 & 3 & 3 & 2 & 2 & 1 & 1 & 1 & 1 & 1 & M \\
\hline $\begin{array}{l}18 \text { Senecio } \\
\text { madagascariensis }\end{array}$ & Fireweed & Herb & 16 & 2 & 0.289 & 0.116 & 1 & 1 & 1 & 4 & 2 & 5 & 4 & 3 & 2 & 2 & $\mathrm{H}$ \\
\hline 19 Senna obtusifolia & Sicklepod & Shrub & 7 & 3 & 0.55 & 0.107 & 1 & 1 & 1 & 4 & 3 & 4 & 3 & 3 & 5 & 3 & $\mathrm{H}$ \\
\hline 20 Lantana camara & Lantana & Shrub & 18 & 5 & 1.417 & 0.102 & 1 & 4 & 3 & 4 & 4 & 3 & 4 & 2 & 3 & 2 & $M$ \\
\hline 21 Cabomba caroliniana & Cabomba & Herb & 9 & 3 & 0.375 & 0.085 & 3 & 4 & 3 & 2 & 2 & 1 & 4 & 1 & 1 & 1 & $M$ \\
\hline $\begin{array}{l}22 \text { Cylindropuntia } \\
\text { spinosior }\end{array}$ & Snake cactus & Succulent & 7 & 1 & 0.1 & 0.080 & 5 & 5 & 5 & 5 & 3 & 3 & 1 & 1 & 1 & 4 & $L$ \\
\hline 23 Anredera cordifolia & Madeira vine & Vine & 11 & 2 & 0.233 & 0.073 & 2 & 3 & 3 & 3 & 2 & 1 & 1 & 1 & 1 & 2 & $M$ \\
\hline $\begin{array}{l}24 \text { Sphagneticola } \\
\text { trilobata syn. Wedelia } \\
\text { trilobata }\end{array}$ & Singapore daisy & Herb & 11 & 3 & 0.45 & 0.070 & 1 & 1 & 1 & 5 & 4 & 5 & 1 & 1 & 1 & 4 & $M$ \\
\hline 25 Schinus terebinthifolius & $\begin{array}{l}\text { Broad-leaved } \\
\text { pepper tree }\end{array}$ & Tree & 12 & 3 & 0.475 & 0.069 & 2 & 5 & 3 & 5 & 3 & 4 & 1 & 1 & 1 & 3 & $\mathrm{H}$ \\
\hline 26 Chromolaena odorata & Siam weed & Shrub & 7 & 4 & 0.447 & 0.067 & 4 & 4 & 3 & 4 & 3 & 3 & 2 & 2 & 2 & 4 & $M$ \\
\hline 27 Annona glabra & Pond apple & Tree & 3 & 2 & 0.167 & 0.067 & 1 & 1 & 1 & 5 & 2 & 1 & 4 & 2 & 1 & 2 & $\mathrm{H}$ \\
\hline 28 Cylindropuntia fulgida & Coral cactus & Succulent & 6 & 3 & 0.235 & 0.063 & 5 & 5 & 5 & 5 & 3 & 3 & 1 & 1 & 1 & 4 & $\mathrm{H}$ \\
\hline 29 Tamarix aphylla & Athel pine & Tree & 8 & 2 & 0.25 & 0.063 & 3 & 3 & 3 & 3 & 2 & 3 & 2 & 2 & 3 & 3 & $\mathrm{H}$ \\
\hline $\begin{array}{l}30 \text { Sporobolus } \\
\text { jacquemontii }\end{array}$ & $\begin{array}{l}\text { American rat's tail } \\
\text { grass }\end{array}$ & Grass & 3 & 2 & 0.15 & 0.060 & 1 & 1 & 2 & 3 & 3 & 5 & 3 & 3 & 3 & 2 & $\mathrm{H}$ \\
\hline 31 Lycium ferocissimum & African boxthorn & Shrub & 13 & 2 & 0.256 & 0.049 & 3 & 3 & 3 & 4 & 3 & 2 & 4 & 3 & 2 & 3 & $M$ \\
\hline $\begin{array}{l}32 \text { Asparagus aethiopicus } \\
\text { 'Sprengeri', A. africanus } \\
\text { \& A. plumosus }\end{array}$ & Asparagus fern & Herb & 13 & 3 & 0.5 & 0.048 & 1 & 1 & 1 & 3 & 3 & 2 & 1 & 3 & 5 & 2 & $\mathrm{H}$ \\
\hline 33 Thunbergia grandiflora & Blue thunbergia & Vine & 6 & 3 & 0.475 & 0.047 & 1 & 3 & 2 & 4 & 2 & 1 & 1 & 2 & 2 & 2 & $\mathrm{H}$ \\
\hline $\begin{array}{l}34 \text { Gymnocoronis } \\
\text { spilanthoides }\end{array}$ & Senegal tea & Herb & 7 & 1 & 0.058 & 0.047 & 1 & 1 & 1 & 2 & 1 & 3 & 1 & 1 & 1 & 1 & $\mathrm{H}$ \\
\hline 35 Baccharis halimifolia & Groundsel bush & Shrub & 12 & 2 & 0.267 & 0.042 & 1 & 1 & 1 & 3 & 3 & 3 & 3 & 4 & 3 & 3 & $\mathrm{H}$ \\
\hline $\begin{array}{l}36 \text { Opuntia \& Nopalea } \\
\text { spp. }\end{array}$ & Prickly pear & Succulent & 16 & 3 & 0.6 & 0.040 & 3 & 4 & 3 & 4 & 3 & 3 & 2 & 2 & 3 & 3 & $\mathrm{H}$ \\
\hline
\end{tabular}




\begin{tabular}{|c|c|c|c|c|c|c|c|c|c|c|c|c|c|c|c|c|c|}
\hline 37 & Cylindropuntia rosea & Hudson pear & Succulent & 2 & 1 & 0.05 & 0.040 & 5 & 5 & 5 & 5 & 3 & 3 & 1 & 1 & 1 & 5 \\
\hline & $\begin{array}{l}\text { Chrysanthemoides } \\
\text { monilifera ssp. } \\
\text { rotundata }\end{array}$ & Bitou bush & Shrub & 2 & 1 & 0.05 & 0.040 & 2 & 3 & 3 & 5 & 4 & 3 & 2 & 1 & 2 & 4 \\
\hline 39 & Ambrosia artemisiifolia & Annual ragweed & Herb & 12 & 2 & 0.233 & 0.038 & 3 & 3 & 1 & 5 & 3 & 5 & 3 & 3 & 5 & 4 \\
\hline 40 & $\begin{array}{l}\text { Cinnamomum } \\
\text { camphora }\end{array}$ & Camphor laurel & Tree & 13 & 3 & 0.435 & 0.035 & 2 & 2 & 2 & 4 & 3 & 2 & 1 & 2 & 1 & 3 \\
\hline 41 & Hygrophila costata & Hygrophila & Herb & 8 & 1 & 0.067 & 0.033 & 3 & 3 & 1 & 3 & 3 & 2 & 1 & 1 & 1 & 2 \\
\hline 42 & $\begin{array}{l}\text { Alternanthera } \\
\text { philoxeroides }\end{array}$ & Alligator weed & Herb & 8 & 2 & 0.167 & 0.032 & 4 & 4 & 5 & 4 & 3 & 4 & 1 & 1 & 1 & 3 \\
\hline 43 & Mimosa pigra & Mimosa pigra & Shrub & 1 & 1 & 0.033 & 0.027 & 4 & 2 & 4 & 4 & 2 & 2 & 3 & 2 & 2 & 3 \\
\hline 44 & Gleditsia triacanthos & Honey locust & Tree & 14 & 2 & 0.261 & 0.026 & 1 & 1 & 2 & 3 & 3 & 3 & 5 & 5 & 2 & 4 \\
\hline 45 & Nassella neesiana & $\begin{array}{l}\text { Chilean needle } \\
\text { grass }\end{array}$ & Grass & 7 & 2 & 0.133 & 0.023 & 1 & 1 & 1 & 4 & 4 & 5 & 1 & 1 & 1 & 3 \\
\hline 46 & Cascabela peruviana & Captain cook tree & Tree & 4 & 2 & 0.15 & 0.023 & 1 & 3 & 2 & 4 & 3 & 2 & 3 & 3 & 3 & 3 \\
\hline 47 & Pennisetum setaceum & $\begin{array}{l}\text { African fountain } \\
\text { grass }\end{array}$ & Grass & 9 & 2 & 0.217 & 0.022 & 1 & 1 & 2 & 3 & 3 & 5 & 3 & 3 & 3 & 2 \\
\hline 48 & $\begin{array}{l}\text { Senegalia pennata } \\
\text { Ssp.insuavis }\end{array}$ & $\begin{array}{l}\text { Cha-om/pennata } \\
\text { wattle }\end{array}$ & Tree & 1 & 1 & 0.025 & 0.020 & 1 & 3 & 2 & 4 & 4 & 3 & 3 & 3 & 3 & 3 \\
\hline 49 & Andropogon gayanus & Gamba grass & Grass & 1 & 1 & 0.025 & 0.020 & 1 & 1 & 1 & 4 & 2 & 5 & 3 & 2 & 5 & 3 \\
\hline 50 & Opuntia microdasys & Bunnny ears & Succulent & 1 & 1 & 0.025 & 0.020 & 4 & 3 & 3 & 5 & 5 & 3 & 4 & 3 & 3 & 4 \\
\hline 51 & Saggitaria Platyphylla & Arrow head & Herb & 1 & 1 & 0.025 & 0.020 & 3 & 3 & 5 & 3 & 3 & 4 & 1 & 1 & 1 & 2 \\
\hline 52 & Gmelina elliptica & Badhara bush & Tree & 1 & 1 & 0.025 & 0.020 & 1 & 1 & 1 & 2 & 2 & 2 & 5 & 5 & 2 & 2 \\
\hline 53 & $\begin{array}{l}\text { Spathodea } \\
\text { campanulata }\end{array}$ & African tulip tree & Tree & 9 & 3 & 0.267 & 0.018 & 3 & 3 & 3 & 4 & 2 & 3 & 5 & 3 & 2 & 3 \\
\hline 54 & Mimosa invisa & $\begin{array}{l}\text { Giant sensitive } \\
\text { plant }\end{array}$ & Shrub & 1 & 1 & 0.033 & 0.017 & 5 & 5 & 5 & 5 & 4 & 5 & 3 & 3 & 4 & 4 \\
\hline 55 & Clidemia hirta & Koster's curse & Shrub & 2 & 1 & 0.02 & 0.016 & 3 & 3 & 3 & 4 & 3 & 3 & 3 & 3 & 2 & 3 \\
\hline 56 & Aristolochia spp. & Dutchman's pipe & Vine & 8 & 1 & 0.067 & 0.013 & 1 & 1 & 1 & 3 & 4 & 4 & 5 & 4 & 5 & 4 \\
\hline 57 & Celtis sinensis & Chinese celtis & Tree & 8 & 1 & 0.067 & 0.013 & 2 & 2 & 1 & 5 & 3 & 4 & 1 & 1 & 1 & 3 \\
\hline 58 & $\begin{array}{l}\text { Cardiospermum } \\
\text { grandiflorum }\end{array}$ & Balloon vine & Vine & 8 & 1 & 0.067 & 0.013 & 3 & 3 & 2 & 3 & 3 & 2 & 1 & 1 & 2 & 3 \\
\hline 59 & Lantana montevidensis & Creeping lantana & Shrub & 7 & 1 & 0.058 & 0.012 & 1 & 1 & 1 & 5 & 4 & 5 & 4 & 1 & 3 & 2 \\
\hline 60 & Opuntia aurantiaca & Tiger pear & Succulent & 5 & 1 & 0.056 & 0.011 & 4 & 3 & 3 & 5 & 4 & 3 & 4 & 4 & 3 & 4 \\
\hline 61 & $\begin{array}{l}\text { Cylindropuntia } \\
\text { imbricata }\end{array}$ & Devils rope pear & Succulent & 2 & 1 & 0.022 & 0.011 & 5 & 5 & 5 & 5 & 3 & 3 & 1 & 1 & 1 & 4 \\
\hline 62 & Neptunia oleracea & Water mimosa & Herb & 6 & 1 & 0.05 & 0.010 & 3 & 1 & 1 & 5 & 5 & 5 & 2 & 1 & 2 & 4 \\
\hline 63 & Hedychium coronarium & White ginger & Shrub & 3 & 1 & 0.025 & 0.005 & 2 & 2 & 2 & 4 & 4 & 3 & 2 & 2 & 2 & 3 \\
\hline
\end{tabular}

grandiflora (blue thunbergia) [33] scored low or negligibly on both axes of risk assessment and risk management feasibility-suggesting limited action (including local eradication) to manage these weeds. Species with medium weed risk assessment and management feasibility scores (including Dolichandra unguis-cati (Cat's claw creeper vine) [17], Hymenachne amplexicaulis (Hymenachne) [12], Bryophyllum spp. (Mother of millions) [7], Senecio madagascariensis (fire weed) [18], Prosopis spp. (Mesquite) [8], Lantana camara (Lantana) [20] will require both targeted control (including use of biocontrol) and site-specific weed management action to curtail their spread into sensitive habitats.

Overall feasibility of control is correlated with estimated ROI for each of the three control options to some but not to a great extent $(r=0.26,0.58,0.42$ for biocontrol, chemical and mechanical control options, respectively; $\mathrm{N}=63, \mathrm{P}<0.05$ ). This suggests that following integration and standardization of management scores, chemical usage option is deemed the most favourable control option, just as detected in the univariate analyses.

\section{Discussion}

Prioritization of IAS for management is increasingly being discussed in the public arena. However few studies, as presented in this work, have combined pest risk assessment with risk management to guide towards informed decision for policy, research and management, especially for post border (established) invaders (Heikkilä, 2011; Auld and Johnson, 2014; Booy et al., 2017). By means of structured elicitation, we engaged stakeholders for inputs, and based on their consensus scores and levels of confidence we have been able to gauge public attitudes regarding perceived threats and management decisions on established IAS in the State of QLD, Australia.

We have applied a prioritization scheme of Booy et al. (2017) which is transparent and traceable to aid in policy and management decision of established IAS of QLD. However, we concurred with the assertion by Auld and Johnson (2014) that a matrix scheme is best thought of as a method to align IAS on a continuum (and hence compare and contrast), rather than give absolute values of their invasiveness/impact and management expediency. This "continuum" approach was necessary as essential empirical data are notoriously difficult to compile for a large number of the species we worked on (e.g., control cost across differing landscape/land use types, IAS density at local and regional levels, or IAS impact on biodiversity, human health and societal economy are not readily available) (Barney et al., 2013; Jardine and Sanchirico, 2018). Also designing and standardization for reliability of risk matrices is still in its infancy (Li et al., 2018). Thus the matrix system at best categorises species into fuzzy management action classes. Nonetheless, within an action class (e.g. prevention of entry/regional eradication for species with high weed risk and high feasibility for management), those with higher scores should be regarded as higher priority (compare Parthenium hysterophorus (Parthenium) [1], Parkinsonia aculeata (Parkinsonia) [4] and Cryptostegia grandiflora (rubber vine) [3] in Fig. 4 in which case 


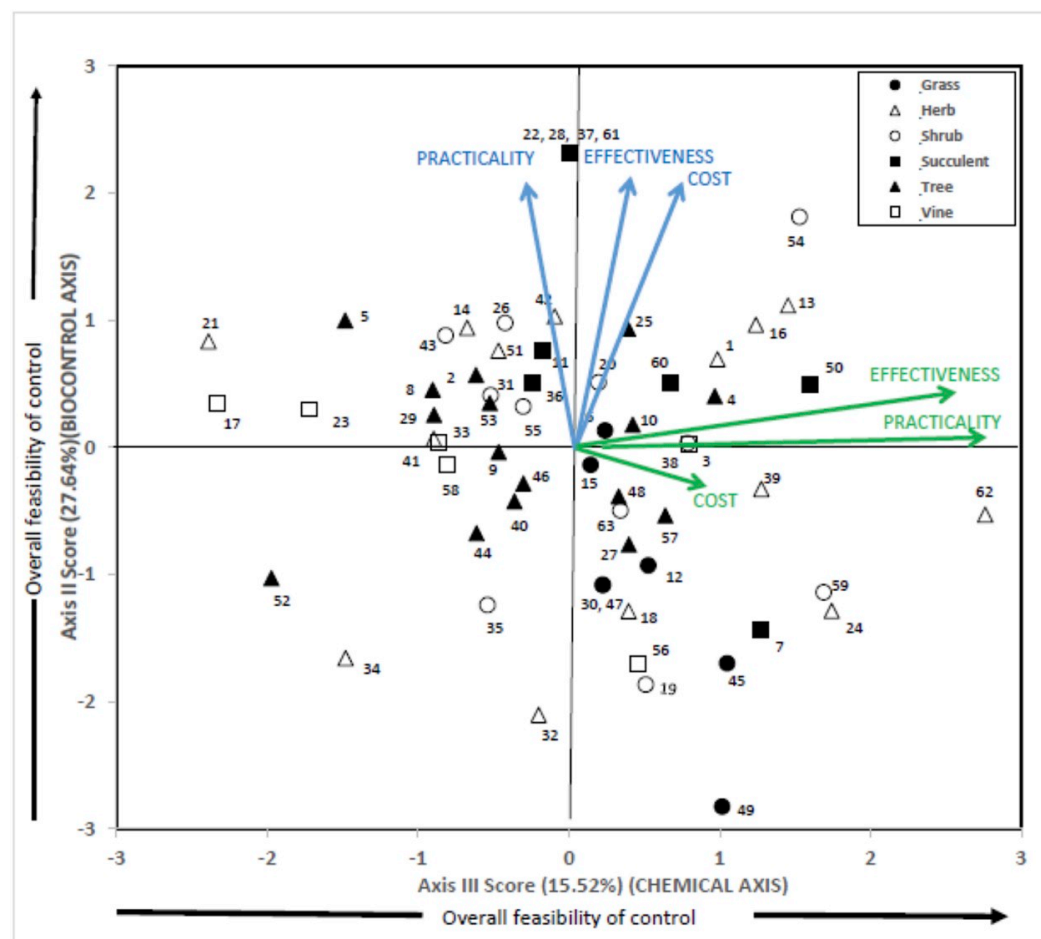

Fig. 3. Position of 63 established IAS (weed) of QLD on major ordination spaces (Axes II-III) using Explanatory Factor Analysis and based on stakeholders perception of components (cost, effectiveness and practicality) of three management criteria (biocontrol, chemical and mechanical). Variation (\%) explained as well as the directions of influence of the management components on each axis are indicated. Individual plant species are identified by numbers (see Table 3 ) and by life form. The contribution of each management component to each major axis is represented by the length and colour of arrows (blue-biocontrol option; and green-chemical option). The overall feasibility of control correlated most with Axis III scores (the chemical control axis, $r=0.56, N=63, P=0.0001$ - indicated by thicker continuous line arrow on the $\mathrm{x}$-axis) and moderately so with Axis II (the biocontrol axis, $\mathrm{r}=0.31 ; \mathrm{N}=63$; $\mathrm{P}<0.01$, indicated by less thicker continuous line on the y-axis). Note that Axis I (the mechanical control axis), though captured the greatest variation in the data set (37.68\%) but is not presented as it was not significantly correlated with the overall feasibility of control $(r=0.11, N=63 ; P=0.23)$, and hence considered of limited utility. (For interpretation of the references to colour in this figure legend, the reader is referred to the Web version of this article.)

Table 4

Top 10 IAS of Queensland, Australia in terms of return on investment for each of three management actions, after adjusting for confidence in the data as provided by the expert stakeholders using Caton et al. (2018) procedure.

\begin{tabular}{|c|c|c|c|}
\hline & Biocontrol & Chemical & Mechanical \\
\hline 1 & Cylindropuntia rosea & Neptunia oleracea & Aristolochia spp. \\
\hline 2 & Cylindropuntia imbricata & Sphagneticola trilobata & Ziziphus mauritiana \\
\hline 3 & Cylindropuntia spinosior & Lantana montevidensis & Gleditsia triacanthos \\
\hline 4 & Mimosa invisa & Mimosa invisa & Gmelina elliptica \\
\hline 5 & Alternanthera philoxeroides & Nassella neesiana & $\begin{array}{l}\text { Ambrosia } \\
\text { artemisiifolia }\end{array}$ \\
\hline 6 & Salvinia molesta & Salvinia molesta & $\begin{array}{l}\text { Cryptostegia } \\
\text { grandiflora }\end{array}$ \\
\hline 7 & Eichhornia crassipes & Eichhornia crassipes & Opuntia aurantiaca \\
\hline 8 & Parthenium hysterophorus & $\begin{array}{l}\text { Parthenium } \\
\text { hysterophorus }\end{array}$ & $\begin{array}{l}\text { Parthenium } \\
\text { hysterophorus }\end{array}$ \\
\hline 9 & Eriocereus spp. & Parkinsonia aculeata & $\begin{array}{l}\text { Parkinsonia } \\
\text { aculeata }\end{array}$ \\
\hline 10 & $\begin{array}{l}\text { Jatropha gossypifolia/ } \\
\text { Chromolaena odorata/Pistia } \\
\text { stratiotes }\end{array}$ & $\begin{array}{l}\text { Ambrosia artemisiifolia/ } \\
\text { Opuntia microdasys }\end{array}$ & Senna obtusifolia \\
\hline
\end{tabular}

Parthenium hysterophorus should be given a higher attention). In the same vein, in the limited/no action - monitoring categories, the Cactaceae family members (Opuntia and Cylindropuntia species [22, 28, 37, 50- Fig. 4]) because of their higher feasibility of management should be given greater attention than Hygrophila costata (Hygrophila) [41], Anredera cordifolia (Madeira vine) [23] and Gymnocoronis spilanthoides (Senegal tea) [34] despite both groups having limited to low impact.

At a coarse scale (using individual species scores), there was no correlation between overall feasibility of control and confidence score attached. This is at odds with our hypothesis in the Introduction section as we had expected that the experts would be more certain about management of IAS that were considered feasible to manage. Although our initial hypothesis could be incorrect, it is also possible that there may have been a cognitive mismatch by the experts between estimating overall feasibility and estimating confidence. However, after splitting the data set into management criterion, significant trends did emerge: trends were positive for chemical control but negative for biocontrol and mechanical control (Table 2). This might suggest that the increasing use of chemical as a control option is favoured with increasing confidence as most herbicides released into the market tend to undergo rigorous research and efficacy trials prior to approval by the regulatory body (The Australian Pesticides and Veterinary Medicines Authority [APVMA]). In contrast, the release of biocontrol agents (whose testing and efficacy, especially in the past) are often diffuse and impact at times unpredictable, some with unintentional consequences (Pearson and Callaway, 2003; Zalucki et al., 2007); mechanical control is also often implemented haphazardly via adaptive management procedures.

In general, few studies have explored uncertainty in model inputs and output in IAS prioritization (but see e.g. Heikkilä, 2011; Booy et al., 2017; Holt et al., 2012), but there is a need to utilise and communicate these sources of variation in species management scores to better enhance the quality of the matrix generated, especially due to the fuzzy nature of the ensuing/resulting management classification. Disregarding uncertainty may lead to suboptimal decisions. Risk assessment schemes should consider uncertainty in input information and output ranking to explicitly integrate uncertainty in decision making (Heikkilä, 2011; Vanderhoeven et al., 2017). By considering uncertainty in this study, we found that the level of uncertainty was lowest (i.e. highest confidence) for the chemical control option (Fig. 1c), as hypothesised in the Introduction and as discussed above. This is in line with existing practice and a strong belief in the use of chemicals to manage established IAS in both agricultural and natural ecosystems (Wagner et al., 2017; Davis and Frisvold, 2017). Chemicals offer several advantages relative to other management methods: they can control invasive alien plants quickly, require little human labour, can be relatively inexpensive (hence why its ROI is highest) and do not directly disturb soil structure. However, caution is still required in their uses as there is evidence that at least some herbicides (despite ongoing research and formulation to decrease their toxicity) pose risks to non-target organisms (Freemark and Boutin, 1995; Wagner et al., 2017) and to human health (Alavanja et al., 2004). We advocate for continuing rigorous evaluation of chemicals for weed control by the registration body (e.g., The PVMA) before being brought to the market. The higher 


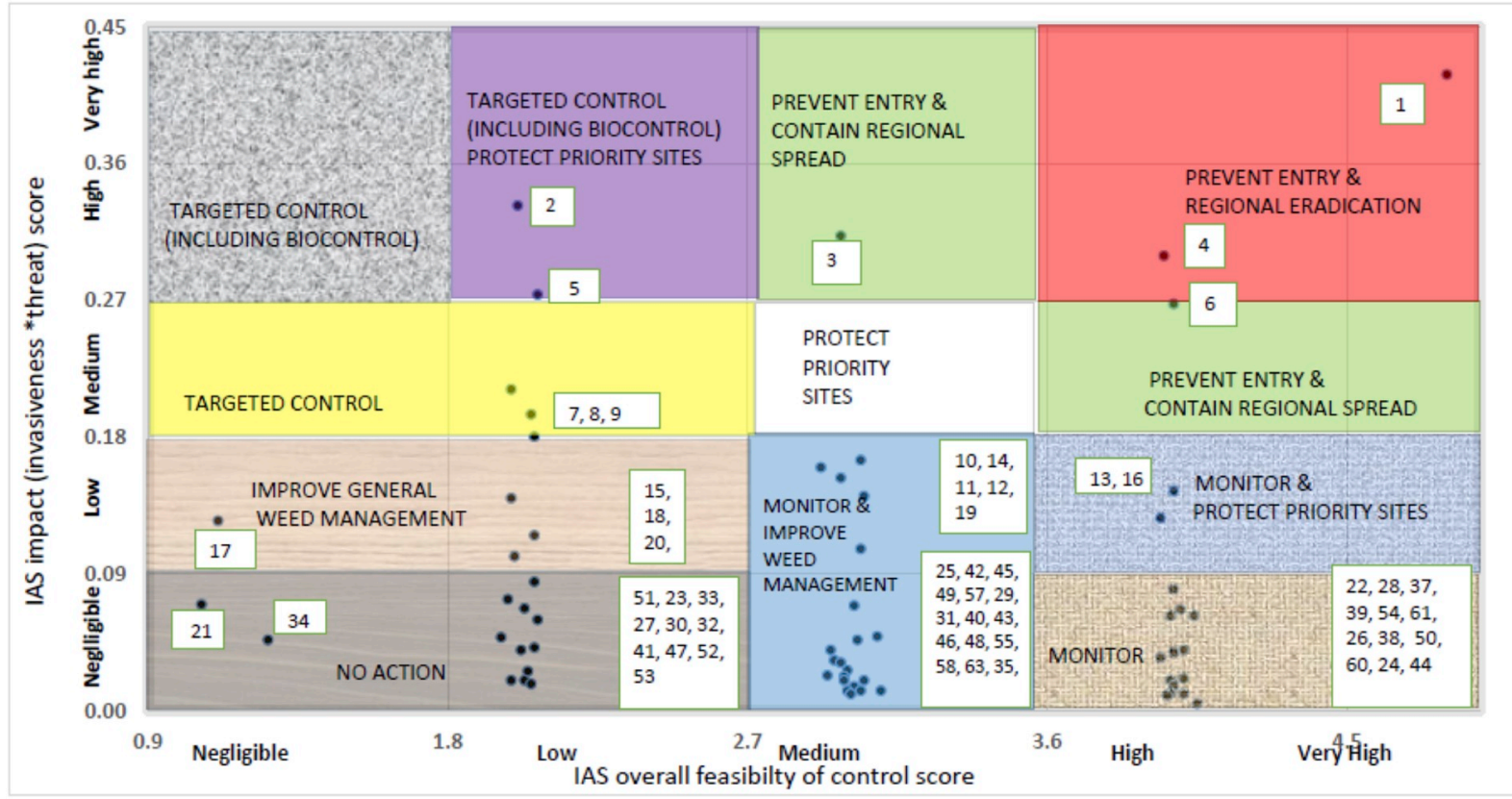

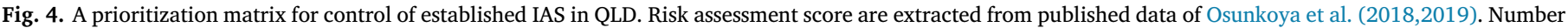

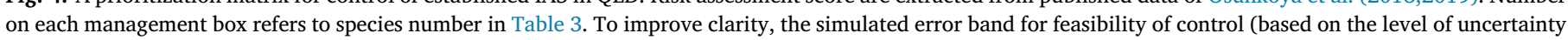

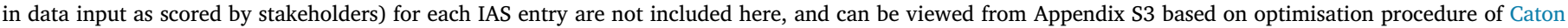

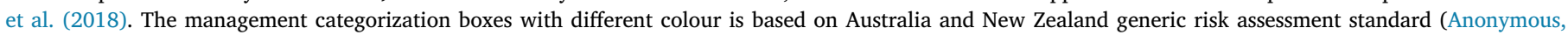
2006). (For interpretation of the references to colour in this figure legend, the reader is referred to the Web version of this article.)

confidence attached to chemical use might also flag that a greater weighting should be given to this management option in future prioritization work.

The cost component of the chemical control was lowest amongst the three management criteria (Fig. 1a), but it made the least (albeit significant) contribution on the ordination Axis III that identified most with the overall feasibility of control (Fig. 3). These observations suggest a lack of internal consistency (i.e., agreement) for this variable. Indeed at the workshop, the cost component remained ambiguous to the expert stakeholders despite attempts to clarify it, suggesting that idea of cost of chemical (and in general most management actions) per unit area per time is difficult to resolve amongst stakeholders due to variation in distribution and density of targeted IAS across landscape scenarios and land use types (Jardine and Sanchirico, 2018). Thus there is a need for a better calibration of this variable in future workshops. The finding that the cost component made the least correlation with the overall feasibility of control is similar to that reported by Booy et al. (2017) for pre-border risk management of 41 IAS of Great Britain. The finding of a lack of correlation of overall feasibility of control with invasiveness or impact is not new (e.g. Hulme, 2012; Booy et al., 2017), indicating that these traits (i.e., invasiveness or impact) carry less weight in management actions on IAS, though they do provide important additional information that will influence resource allocation and the timing of management.

We found that terrestrial IAS did not necessarily receive significantly higher management scores than their aquatic counterpart, in contrast with the findings of Simberloff (2009) and Booy et al. (2017) and our expectation (see Introduction). The above mentioned authors had postulated that variation in stakeholders scores will occur in response to perception of differences in the ecology of these two groups of IAS. No difference in the management score between IAS of the two habitats could also simply be an artefact of a major difference in our sample size ( $\mathrm{N}=11$ and 52 for aquatic vs terrestrial IAS), resulting in a lack of statistical power.

Succulents (e.g. the Cactaceae family) and herbs are more likely to be better manage via biocontrol than any other life history groups, partly because of the perceived greater (historical) success of use of biological agents on such groups around the globe (Julien et al., 2012). Indeed in this study there was an evidence to support this claim (Fig. 3; Appendices S2 and S3); succulents and herbs loaded positively and significantly differently on the biocontrol axis (Axis II) of the species ordination compared to other life form groups. It is also interesting to note that monocots (e.g., grasses), as a group, were the least likely to be effectively manage using biocontrol (Fig. 2; Appendix S2). This reflects the widely held perception and current practice in weed biocontrol (as hypothesised in the Introduction): avoid targeting grasses because of the economic importance of many grass species and the perception that a general lack of species-specific secondary chemistry among grasses would result in a lack of host-specific herbivores, thus threatening the safety of non-target species (Pemberton, 2000; Yobo et al., 2009; Casagrande et al., 2018). The overall lower confidence and management feasibility ascribed to biocontrol option by stakeholders (Fig. 1b) in this work can only fuel this belief. Indeed there are no known approved and released biocontrol agents for monocots among the 103 QLD IAS identified by on-ground stakeholders (Osunkoya et al., 2019 but see Vitelli et al. (2017) for a recent promising agent-the leaf smut fungus-on Sporobolus pyramidalis and $S$. natalensis (giant rat tail grasses) [6]). In recent years, an increasing number of authors have suggested that the biocontrol research community should move away from such avoidance beliefs and prejudice, as there are an enormous diversity of herbivores with host-specificity criteria for monocots just as there are in other targeted plant life forms in current weed biocontrol programs (Julien, 2006; Casagrande et al., 2018).

\section{Summary and conclusions}

We found out that expert stakeholders were most favourable and confident about the use of chemical (and to some extent biocontrol) for management of IAS, with practicality and effectiveness rather than cost as the main driver variables. However, perceived management efficacy, irrespective of control option, was influenced by IAS life form: stakeholders were more optimistic about management of succulents and 
herbs/shrubs and least optimistic about monocots (grasses) and woody vines. Management feasibility did not differ between habitat invaded (aquatic vs terrestrial), though the null effect could be caused by the low statistical power due to low sample size for the aquatic group.

We have applied a prioritization scheme (Booy et al., 2017) to aid in policy and management decision about established IAS of QLD. However, the methodology can benefit from further refinement, including cost-benefit optimisation of the management criteria (Firn et al., 2015; Courtois et al., 2018). Our estimation of spread was based on simple counts of IAS presence and range distribution across local governments and regions in QLD. Whilst we have shown that this proxy indeed is a good measure of invasiveness (Osunkoya et al., 2018; 2019), the estimate, and hence risk assessment, will benefit by incorporating other drivers of invasiveness, including ultimate area of occupation, density and spread rate, and invasion pathways. These are data that are hard to compile in a multi-species setting like in this study but their importance as source/s of input uncertainty and sensitivity of outputs are increasingly being recognised, and resources are increasingly being provided to improve the precision of model outputs (Hulme et al., 2013;McGeoch et al., 2016; Vanderhoeven et al., 2017; Caton et al., 2018).

As in many studies (e.g., Darin et al., 2011; Kumschick et al.,2012; Caton et al., 2018), we have shied away from the issue of attaching weighting to the criteria used in the ranking exercise, though we are aware some authors have advocated for it (Nel et al., 2004; Virtue, 2010; Downey et al., 2010; Benke et al., 2011; Heikkilä, 2011; Vanderhoeven et al., 2017). How to weigh components or decision criteria in species risk assessments is an open question (Leung et al., 2012), especially to avoid double counting effects. Consequently, we have used a simple aggregation and/or integration approach as we think it best serves the purpose of the research. Additionally, our data gathering process and presentation is transparent and hence weighting can be applied to the main criteria and/or their components in the future, if need be.

We have addressed uncertainty in data inputs and the likely effect on model output in a simplified way in this study as it provides additional information to assessor and decision makers. Formal methodology and user-friendly interface/visualizing programs to incorporate uncertainty in species prioritization exercise is just beginning to emerge (Holt et al., 2012; Caton et al., 2018), and should be applied in future work. Risk scores and consequently management decision need to be reviewed periodically due to changes in the level of uncertainty attached and in light of new information (Robertson et al., 2003; Caton et al., 2018; Hemming et al., 2018; Osunkoya et al., 2019). Nonetheless, the risk assessment-risk management matrix we have presented offers great opportunity for contingency planning and efficient resource allocation relating to weed prioritization action.

\section{Acknowledgements}

The study was funded by the Queensland Department of Agriculture \& Fisheries. The effort of many stakeholders across the state of Queensland, Australia who attended the IAS feasibility of control and management workshop leading to this paper is acknowledged and appreciated. Christine Perrett and Jason Callander helped greatly in data scribing and collation, while Christine Rinehart did a great job as the workshop facilitator.

\section{Appendix A. Supplementary data}

Supplementary data related to this article can be found at https:// doi.org/10.1016/j.jenvman.2019.05.052.

\section{References}

Alavanja, M.C., Hoppin, J.A., Kamel, F., 2004. Health effects of chronic pesticide exposure: cancer and neurotoxicity. Annu. Rev. Public Health 25, 155-197.
Anonymous, 2006. HB 294-2006 National Post-Border Weed Risk Management Protocol.Standards Australia International Ltd.; Auckland: Standards New Zealand. CRC Australian Weed Management Sydney, Adelaide.

Auld, B.A., Johnson, S.B., 2014. Invasive alien plant management. CAB Review 9, 1-12 doi.

Baglin, J., 2014. Improving your exploratory factor analysis for ordinal data: a demonstration using FACTOR. PARE 19, 1-15.

Baker, R.H., Benninga, J., Bremmer, J., Brunel, S., Dupin, M., Eyre, D., Ilieva, Z., Jarošík, V., Kehlenbeck, H., Kriticos, D.J., 2012. A decision-support scheme for mapping endangered areas in pest risk analysis. EPPO Bull. 42, 65-73.

Barney, J.N., Tekiela, D.R., Dollete, E.S., Tomasek, B.J., 2013. What is the "real" impact of invasive plant species? Front. Ecol. Environ. 11, 322-329.

Bickel, T.O., 2017. Processes and factors that affect regeneration and establishment of the invasive aquatic plant Cabomba caroliniana (Cabomba). Hydrobiologia 788, 157-168.

Benke, K.K., Steel, J.L., Weiss, J.E., 2011. Risk assessment models for invasive species: uncertainty in rankings from multi-criteria analysis. Biol. Invasions 13, 239-253.

Booy, O., Mill, A.C., Roy, H.E., Hiley, A., Moore, N., Robertson, P., Baker, S., Brazier, M., Bue, M., Bullock, R., 2017. Risk management to prioritise the eradication of new and emerging invasive non-native species. Biol. Invasions 19, 2401-2417.

Burgman, M.A., 2015. Trusting Judgements: How to get the best Out of experts. Cambridge University Press, UK.

Casagrande, R.A., Häfliger, P., Hinz, H.L., Tewksbury, L., Blossey, B., 2018. Grasses as appropriate targets in weed biocontrol: is the common reed, Phragmites australis, an anomaly? BioControl 63, 391-403.

Caton, B.P., Koop, A.L., Fowler, L., Newton, L., Kohl, L., 2018. Quantitative uncertainty analysis for a weed risk assessment system. Risk Anal. 38, 1972-1987.

Cook, D., Proctor, W., 2007. Assessing the threat of exotic plant pests. Ecol. Econ. 63 , 594-604.

Courtois, P., Figuieres, C., Mulier, C., Weill, J., 2018. A cost-benefit approach for prioritizing invasive species. Ecol. Econ. 146 607-120.

Darin, G.M.S., Schoenig, S., Barney, J.N., Panetta, F.D., DiTomaso, J.M., 2011. WHIPPET: a novel tool for prioritizing invasive plant populations for regional eradication. J. Environ. Manag. 92, 131-139.

Davis, A.S., Frisvold, G.B., 2017. Are herbicides a once in a century method of weed control? Pest Manag. Sci. 73, 2209-2220.

Downey, P.O., Scanlon, T.J., Hosking, J.R., 2010. Prioritizing weed species based on their threat and ability to impact on biodiversity: a case study from New South Wales. Plant Protect. Q. 25, 111-126.

Firn, J., Martin, T.G., Chadès, I., Walters, B., Hayes, J., Nicol, S., Carwardine, J., 2015. Priority threat management of non-native plants to maintain ecosystem integrity across heterogeneous landscapes. J. Appl. Ecol. 52, 1135-1144.

Freemark, K., Boutin, C., 1995. Impacts of agricultural herbicide use on terrestrial wildlife in temperate landscapes: a review with special reference to North America. Agric. Ecosyst. Environ. 52, 67-91.

Heikkilä, J., 2011. A review of risk prioritisation schemes of pathogens, pests and weeds: principles and practices. Agric. Food Sci. 20, 15-28.

Hemming, V., Burgman, M.A., Hanea, A.M., McBride, M.F., Wintle, B.C., 2018. A practical guide to structured expert elicitation using the IDEA protocol. Methods Ecol. Evol. 9, 169-180.

Holt, J., Leach, A., Knight, J., Griessinger, D., MacLeod, A., Van der Gaag, D., Schrader, G., Mumford, J., 2012. Tools for visualizing and integrating pest risk assessment ratings and uncertainties. EPPO Bull. 42, 35-41.

Hulme, P.E., 2012. Weed risk assessment: a way forward or a waste of time? J. Appl. Ecol. 49, 10-19.

Hulme, P.E., Pyšek, P., Jarošík, V., Pergl, J., Schaffner, U., Vilà, M., 2013. Bias and error in understanding plant invasion impacts. Trends Ecol. Evol. 28, 212-218.

Hussner, A., Stiers, I., Verhofstad, M., Bakker, E., Grutters, B., Haury, J., Van Valkenburg, J., Brundu, G., Newman, J., Clayton, J., 2017. Management and control methods of invasive alien freshwater aquatic plants: a review. Aquat. Bot. 136, 112-137.

Jardine, S.L., Sanchirico, J.N., 2018. Estimating the cost of invasive species control. J. Environ. Econ. Manag. 87, 242-257.

Julien, M.H., McFadyen, R.E., Cullen, J., 2012. Biological Control of Weeds in Australia CSIRO Publishing, Australia.

Julien, M., 2006. Biological control of rangeland weeds in Australia. Rangel. J. 28, 47-54.

Kumschick, S., Bacher, S., Dawson, W., Heikkilä, J., Sendek, A., Pluess, T., Robinson, T., Kühn, I., 2012. A conceptual framework for prioritization of invasive alien species for management according to their impact. NeoBiota 15, 69-100.

Leung, B., Roura-Pascual, N., Bacher, S., Heikkilä, J., Brotons, L., Burgman, M.A., Dehnen Schmutz, K., Essl, F., Hulme, P.E., Richardson, D.M., 2012. TEASIng apart alien species risk assessments: a framework for best practices. Ecol. Lett. 15, 1475-1493.

Li, J., Bao, C., Wu, D., 2018. How to design rating schemes of risk matrices: a sequential updating approach. Risk Anal. 38, 99-117.

Liu, S., Sheppard, A., Kriticos, D., Cook, D., 2011. Incorporating uncertainty and social values in managing invasive alien species: a deliberative multi-criteria evaluation approach. Biol. Invasions 13, 2323-2337.

Lodge, D.M., Simonin, P.W., Burgiel, S.W., Keller, R.P., Bossenbroek, J.M., Jerde, C.L Kramer, A.M., Rutherford, E.S., Barnes, M.A., Wittmann, M.E., 2016. Risk analysis and bioeconomics of invasive species to inform policy and management. Annu. Rev. Environ. Resour. 41, 453-488.

Lorenzo-Seva, U., Ferrando, P.J., 2006. FACTOR: a computer program to fit the exploratory factor analysis model. Behav. Res. Methods 38, 88-91.

Martin, T.G., Burgman, M.A., Fidler, F., Kuhnert, P.M., Low-Choy, S., McBride, M., Mengersen, K., 2012. Eliciting expert knowledge in conservation science. Conserv. Biol. 26, 29-38.

Mastrandrea, M.D., Mach, K.J., Plattner, G.-K., Edenhofer, O., Stocker, T.F., Field, C.B., Ebi, K.L., Matschoss, P.R., 2011. The IPCC AR5 guidance note on consistent treatment 
of uncertainties: a common approach across the working groups. Clim. Change 108, 675-691.

McGeoch, M.A., Genovesi, P., Bellingham, P.J., Costello, M.J., McGrannachan, C., Sheppard, A., 2016. Prioritizing species, pathways, and sites to achieve conservation targets fo biological invasion. Biol. Invasions 18, 299-314.

McGeoch, M.A., Spear, D., Kleynhans, E.J., Marais, E., 2012. Uncertainty in invasive alien species listing. Ecol. Appl. 22, 959-971.

Nel, J., Richardson, D., Rouget, M., Mgidi, T., Mdzeke, N., Le Maitre, D.C., Van Wilgen, B., Schonegevel, L., Henderson, L., Neser, S., 2004. A proposed classification of invasive alien plant species in South Africa: towards prioritizing species and areas for management action: working for water. South Afr. J. Sci. 100, 53-64.

Osunkoya, O.O., Froese, J., Nicol, S., Perrett, C., Moore, K., Callander, J., Campbell, S., 2019. A risk-based inventory of invasive plant species of Queensland: regional, ecological and floristic insights. Austral Ecol (in press).

Osunkoya, O.O., Perrett, C., Moore, K., Nicol, S., Froese, J., Gooding, K., Campbell, S., 2018. An inventory of Queensland prioritized invasive species for management an research. In: Johnson, S., Weston, L., Wu, H., Auld, B. (Eds.), $21^{\text {st }}$ Australasian Weeds Conference. The Weeds Society of NSW, Sydney, Australia, pp. 392-396.

Osunkoya, O.O., Perrett, C., 2014. Evaluation of restoration of vegetation infested with cat's claw creeper vine (Dolichandra unguis-cati): soil seed bank response to herbicide and physical removal. In: Baker, M. (Ed.), $19^{\text {th }}$ Australasian Weeds Conference. Tasmanian Weed Society, Tasmania, Hobart, pp. 219-222.

Osunkoya, O.O., Perrett, C., Fernando, C., Clark, C., Raghu, S., 2013. Modeling population growth and site specific control of the invasive Lantana camara L.(Verbenaceae) under differing fire regimes. Popul. Ecol. 55, 291-303.

Panetta, F., Gooden, B., 2017. Managing for biodiversity: impact and action thresholds for invasive plants in natural ecosystems. NeoBiota 34, 53-66.

Pearson, D.E., Ortega, Y.K., Eren, Ö., Hierro, J.L., 2016. Quantifying "apparent" impact and distinguishing impact from invasiveness in multispecies plant invasions. Ecol. Appl. 26, 162-173.

Pearson, D.E., Callaway, R.M., 2003. Indirect effects of host-specific biological control agents. 18. Trends Ecol. Evol, pp. 456-461.

Pemberton, R.W., 1996. The potential of biological control for the suppression of invasive weeds of southern environments. Castanea, pp. 313-319.

Pemberton, R.W., 2000. Predictable risk to native plants in weed biological control. Oecologia 125, 489-494.

Randall, J.M., Morse, L.E., Benton, N., Hiebert, R., Lu, S., Killeffer, T., 2008. The invasive species assessment protocol: a tool for creating regional and national lists of invasive nonnative plants that negatively impact biodiversity. Invasive Plant Sci. Manag. 1, 36-49.

Robertson, M., Villet, M., Fairbanks, D., Henderson, L., Higgins, S., Hoffmann, J., Le Maitre, D.C., Palmer, A., Riggs, I., Shackleton, C., 2003. A proposed prioritization system for the management of invasive alien plants in South Africa: research in action. South Afr. J. Sci. 99, 37-43.

Simberloff, D., 2009. We can eliminate invasions or live with them. Successful management projects. Biol. Invasions 11, 149-157.

Vanderhoeven, S., Branquart, E., Casaer, J., D’hondt, B., Hulme, P.E., Shwartz, A., Strubbe, D., Turbé, A., Verreycken, H., Adriaens, T., 2017. Beyond protocols: improving the reliability of expert-based risk analysis underpinning invasive species policies. Biol. Invasions 19, 2507-2517.

Virtue, J.G., 2010. South Australia's weed risk management system. Plant Protect. Q. 25, 90-94.

Vitelli, J., Tan, Y., Riding, N., Holdom, D., Chamberlain, A., Shivas, R., 2017. First record of Ustilago sporoboli-indici in Australia. Australas. Plant Dis. Notes 12, 52.

Wagner, V., Antunes, P.M., Irvine, M., Nelson, C.R., 2017. Herbicide usage for invasive non- native plant management in wildland areas of North America. J. Appl. Ecol. 54, 198-204.

Yobo, K.S., Laing, M.D., Palmer, W.A., Shivas, R.G., 2009. Evaluation of Ustilago sporoboliindici as a classical biological control agent for invasive Sporobolus grasses in Australia. Biol. Control 50, 7-12.

Zalucki, M., Day, M., Playford, J., 2007. Will biological control of Lantana camara ever succeed? Patterns, processes and prospects. Biol. Control 42, 251-261. 